\title{
Nurse-sensitive outcomes of advanced practice
}

\author{
Gail L. Ingersoll EdD RN FAAN \\ Director of Clinical Nursing Research, Strong Memorial Hospital, Rochester, \\ New York, New York \\ Elaine McIntosh MSN RN \\ Director, Nurse-Managed Centers and Lecturer, University of Michigan School \\ of Nursing, Ann Arbor, Michigan \\ and Mamie Williams MPH \\ Research Associate, Vanderbilt University School of Nursing, Nashville, \\ Tennessee, USA
}

Accepted for publication 12 July 2000

INGERSOLL G.L., MCINTOSH E. \& WILLIAMS M. (2000) Journal of Advanced Nursing 32(5), 1272-1281

\section{Nurse-sensitive outcomes of advanced practice}

Advanced practice nurses (APNs) in the USA are registered nurses who hold masters or doctoral degrees in a specialized area of nursing. They provide advanced clinical care to clients, manage health care systems and influence health care decision-making through expert clinical reasoning and research and theory-based action. APN impact on health care outcomes is supported by studies using physician-focused indicators, although a few studies have identified several that are sensitive to or reflective of advanced practice nursing. A modified Delphi survey was conducted during May 1997December 1998 to determine the outcome indicators APNs recommend for use in measuring their effect on care delivery outcomes. A convenience sample of 66 APNs attending a statewide outcomes conference identified 27 potential outcome indicators. These indicators were included in a mailed survey sent to APNs working in Tennessee. Respondents were asked to rate each indicator for validity, sensitivity, feasibility, utility and cost. In the second round of the survey, they were asked whether or not they agreed with the rank ordering of indicators, which was determined by the means calculated from responses in the first round. The 10 highest ranked indicators were satisfaction with care delivery, symptom resolution/reduction, perception of being well cared for, compliance/adherence with treatment plan, knowledge of patients and families, trust of care provider, collaboration among care providers, frequency and type of procedures ordered and quality of life. APNs identified both direct and indirect measures of effect on care delivery outcomes. Some of these are currently used as indicators of advanced practice, but many are not. 
Additional research is needed to determine whether the indicators proposed are valid and sensitive to advanced practice care by nurses.

Keywords: advanced practice, Delphi survey, outcome indicators, nurse-sensitive outcomes

\section{INTRODUCTION}

Policy makers and health care economists in the USA are promoting the use of advanced practice nurses (APNs) to contain health costs (Safriet 1992, Buerhaus 1998). APNs are registered nurses who hold masters or doctoral degrees in a specialized area of nursing and who provide advanced clinical care to clients. They also manage health care systems and influence health care decision making through expert clinical reasoning and research and theorybased action (adapted from American Nurses Association (ANA) 1996b and Brown 1998).

Proponents of the APN as primary care provider cite several studies demonstrating the equivalence or superiority of APN outcomes when compared with physicians practising in comparable settings and with similar clientele (Safriet 1992, Mundinger 1994, Reed \& Selleck 1996). Nonetheless, some resistance to APNs remains. Detractors question the extent to which APNs contribute a value added component to care delivery and mention the uncertainty about which conditions and settings are most likely to benefit from APNs (Sox 2000).

The inconsistent use of reliable and valid indicators of APN practice has contributed to these concerns. Moreover, recent efforts to standardize the measurement of care delivery outcomes have not improved the situation. Outcomes proposed for standardized reporting have been developed largely with physician care providers in mind. Consequently, we have no assurance that they are appropriate or sensitive to APN practice (Kelly et al. 1994, Ingersoll 1995). Therefore, a study was undertaken to determine the indicators APNs believe are most appropriate for the measurement of APN effect on care delivery outcomes.

\section{BACKGROUND}

Two leadership groups in the US, the American Association of Colleges of Nursing and the American Organization of Nurse Executives, have emphasized the need for documenting the effect of advanced practice nursing on care delivery outcome (Anderson \& Bednash 1996). These two organizations have recommended the development of large intervention and outcomes focused data sets amenable to comparative analyses across practitioners and settings. Without compelling evidence of the reliability and validity of these databases, however, no guarantee can be made that the findings will be used by decision-makers no matter how widespread or available the data. Moreover, the databases actually may be harmful to decisionmaking if actions are based on the mistaken assumption that the outcomes are reflective of and sensitive to advanced practice nursing.

\section{Measurement of patient outcomes}

The current focus on outcomes assessment is largely directed toward containing health costs rather than understanding the scientific basis for the clinical interventions (Irvine et al. 1998). Few reports mention the underlying frameworks used to propose the causal relationship between outcomes measured and care provided (Sidani \& Irvine 1999). In addition, when reviews of care delivery outcomes are described, they tend to focus exclusively on the categorization of commonly mentioned indicators. Reviews in the past 10 years have produced anywhere from 4 to 15 categories of indicators. Hegyvary (1991) identified four: clinical, functional, financial and perceptual. Irvine et al. (1998) described six - prevention of complications; clinical outcomes, including those associated with symptom control and indication of health status; knowledge of disease and its appropriate treatment; functional health outcomes that encompass the physical, mental, cognitive and social functioning associated with self-care; patient satisfaction with care and cost of care. The greatest number of indicators were developed by Lang and Marek (1990), who listed 15: physiological, psychosocial, functional, behavioural, knowledge, symptom control, home maintenance, well-being, goal attainment, patient satisfaction, safety, nursing diagnosis resolution, frequency of service, cost and rehospitalization. Several of these measures are global in nature (well-being, safety), while others are highly specific (frequency of service, rehospitalization). Clearly, the need exists for validating and testing the categories to determine which are the most appropriate.

Patients and families, care providers, medical records, population surveys and existing administrative databases are the most common sources of outcome data. Each of these sources provides information about different aspects of health care and each is limited in its ability to meet the full range of researchers', practitioners' and decisionmakers' needs. As a result, multiple measures from multiple sources are the standard, although this is costly 
and makes comparison across sites or over time difficult (Mark \& Burleson 1995). To address this problem, standardized outcome measures and a nursing minimum data set have been proposed (Barrell et al. 1997, Mitchell et al. 1997, Buerhaus 1998).

\section{APN-sensitive outcome measures}

Discussions of standardized databases have only recently begun to mention the need for nurse-sensitive measures of outcome (Jennings 1991, Hylka \& Beschle 1995, Maas et al. 1996). Recommendations in the past have focused on determining the essential components of a 'nursing minimum data set' (Werley et al. 1991) and on developing a taxonomy of nursing interventions (McCloskey \& Bulechek 1996).

The original work concerning the nursing minimum data set stressed the need for comparing nursing data across settings and with different populations (Werley et al. 1991); no mention is made of nurse-sensitive patient outcomes. The minimum data set proposed by early developers incorporated three primarily administrative components - nursing care elements, patient or client demographic elements and service elements. In nursing care elements, there is a notation of nursing outcome, although no information is provided about the ways in which these outcome measures are targeted at patients rather than the providers.

Maas et al. (1996) updated the minimum data set and refocused the outcomes segment to include nurse-sensitive patient outcomes. They subsequently developed a nursing outcomes classification system derived from the literature and validated by researchers and clinicians (Johnson \& Maas 1997). These investigators intend to field test their indicators, although their focus is on the identification of outcome measures sensitive to nursing practice generally rather than to APNs in particular.

The American Nurses Association (ANA) (1996a) also has proposed a set of nursing quality indicators, although these are targeted solely for acute care settings. Furthermore, they focus on quality rather than outcomes, which results in a mixture of structure, process and outcome measures. These indicators also are not specific to APN practice.

Outcomes of APN care delivery have been measured in several studies conducted over the past 10 years. Each of these studies has demonstrated comparable or superior outcomes when APN care is compared with physician practice. The gold standard used in each of these studies is physician practice (Ingersoll 1995). This exclusive focus on physician indicators precludes the inclusion of measures that address behaviours more commonly associated with nurse directed care delivery, for example, teaching, counselling and coordination of services.
As a first step in the identification of APN-sensitive outcomes, a two-phased modified Delphi survey was conducted in Tennessee. The purpose of the Delphi was to identify a set of APN-sensitive outcome indicators that could be tested by APNs and researchers.

\section{METHOD}

Participation in all aspects of the study was voluntary. Steps taken to protect the rights of subjects were reviewed and approved by the University's institutional review board. Return of completed questionnaires was considered as consent to participate in the pilot and subsequent mailed survey.

The first phase of the study involved identification of a proposed set of core outcome indicators relevant to APN care delivery regardless of practice site or specialty practice. In this phase, a convenience sample of 66 APNs attending a state-wide conference on care delivery outcomes was asked to brainstorm and to identify indicators they used to measure their effect on patients and families. They also were asked to suggest additional indicators they believed might be useful for measuring APN impact on care delivery outcome.

Five groups of 10-15 APNs were convened at separate tables. Each group was facilitated by a member of the research team involved in the initial phase of the study. The project team facilitators were trained prior to the session. Facilitators were asked to encourage participation by all APNs and to clarify unclear or incomplete statements.

Brainstorming sessions were audiotaped and transcribed verbatim. Transcripts were reviewed for statements about specific indicators or for discussions that alluded to an indicator, but did not assign a specific name to it. Two members of the research team reviewed the transcripts and identified each segment. A table listing the names of indicators and the frequency with which they were identified was created. Where the discussion groups applied similar yet slightly different terms to the same concept, researcher consensus was used to assign a single term. When possible, the term selected was based on indicators mentioned in the literature. When not, discussion among the group of clinical and research experts was used to assign a term.

Through this process, 27 outcome indicators were identified. The research team subsequently defined each of the indicators and included the definitions in the pilot testing and first round of questionnaires. The definitions were drawn from the literature when possible and adapted from the literature when not. Definitions were included to reduce the potential for differences in respondent interpretation. Indicators were listed alphabetically for objectivity.

In the pilot-testing segment of the study, 10 practising APN faculty were asked to complete the questionnaire and 
to record the amount of time required to complete it; 8 of the 10 did so. APN faculty also were asked to identify any confusing terms or definitions and to note areas of concern about the questionnaire as a whole. Based on this feedback, minor revisions were made to outcome indicator definitions. The time required to complete the questionnaire ranged from about 20-60 minutes (mode = 30 minutes).

The survey sample consisted of all 1190 APNs working in Tennessee who were certified to practice as an advanced practitioner. Certification requirements included documentation of graduate education or specialized training or demonstration of competency through national certification exam. Physicians' assistants (PAs) and certified nurse anaesthetists (CNAs), whose scope of practice differs, were excluded from the sample (Tennessee Board of Nursing (TBN) 1994, Division of Health-Related Boards 1995). Estimates available from databases at the Tennessee Nurses Association (TNA) (unpublished data) and the TBN suggested the number of APNs certified to practice was 1090 at the start of the study. A third research-based source (P. Smith \& B. Jolley, unpublished letter) also was used to validate the lists provided by the TNA and the TBN. The three lists were cross-checked and a final list of practising APNs was prepared. In the first round of the survey, APNs were asked to respond to a series of questions pertaining to each of the outcomes proposed. Questions focused on the potential cost, feasibility, relevance, burden and usefulness of the outcomes for assessment of APN impact. In a few cases (cost, knowledge and skill of other care providers, productivity and student awareness of need to evaluate APN services), one or more items were removed because of their incompatibility with the indicator proposed.

Two weeks after the initial mailing, a letter was sent thanking those who had responded and encouraging those who had not, to return the questionnaire as soon as possible. Repeat mailings of questionnaires did not occur because of the associated costs. In the second round of questionnaires, indicators were ranked by mean score, which was derived from the indicator options for each. Negatively stated items were reverse coded prior to the calculation of means. Higher mean scores were indicative of more favourable responses by APNs. Those APNs who responded to the first mailing were sent the second and were asked to note whether or not they agreed with the ranking of the indicator. They also were asked whether they would recommend keeping the indicator and whether or not they would use the indicator in practice. Dichotomous response options (yes/no) were used in this segment of the survey. Descriptive statistics were used to analyse the data. Mean scores were computed for each indicator using the responses to questions posed in round one of the survey (Table 1). ANOVA with Bonferoni post hoc comparison was used to determine differences according to respondent characteristics.

\section{RESULTS}

Despite the availability of an incentive to encourage participant response, return rates for the initial and subsequent mailings were low. Of the initial 1190 questionnaires mailed, $174(15 \%)$ were returned because of incorrect or outdated mailing address or because the recipient was not practising as an APN. A total of 177 $(15 \%)$ returned useable questionnaries in the first mailing.

Assessment cannot be made as to whether respondents differed from nonrespondents because of concern about the accuracy of the mailing lists used. In light of these limitations, findings should be considered indicative of the group of APNs who responded, which may or may not be reflective of APNs practising in Tennessee or elsewhere. The majority of respondents were masters prepared $(85.9 \% ; n=152)$ and were between the ages of 35 and 54 years $(79 \% ; n=139)$. Slightly more than one-third of the sample $(n=62 ; 35 \%)$ had worked as an APN for 1-5 years. A total of 60 (34\%) had worked for more than 10 years as an APN and $41(23 \%)$ had worked between 6 and 10 years.

Respondents represented all regions of the state, 68 $(38 \%)$ practised in the middle region of the state, $60(34 \%)$ in the eastern portion of the state and $41(23 \%)$ in the western region; 8 responses were missing. Most respondents worked in urban $(47 \% ; n=83)$ or mixed urban/rural $(26 \% ; n=46)$ areas. Primary sites of practice included private practice $(29 \% ; n=52)$, acute care $(24 \% ; n=42)$, community health agency $(20 \% ; n=35)$ and other $(22 \%$; $n=39) ; 2 \cdot 8 \%(n=5)$ were in independent practice.

Respondents were split approximately in half as to designation as primary care provider, with $46 \%(n=81)$ reporting approved reimbursement status for care provided. The majority were certified as family nurse practitioners $(43 \% ; n=76)$; the next most frequently identified certification was as clinical nurse specialist $10 \%$; $n=18$ ). A range of other specialty areas was found among the remaining respondents. Usual daily caseload ranged from 10 to 20 patients $(48 \% ; n=84)$, followed by $21-50$ patients $(29 \% ; n=52)$ and less than $10(18 \% ; n=32)$; four respondents $(2 \%)$ saw greater than 50 patients per day.

Coefficients alpha for the items addressing each of the proposed indicators ranged from 0.64 for self-directedness (patient or parent/guardian for children) to 0.90 for functional status, indicating acceptable internal consistency reliability for the first stage of instrument development. No attempts were made to assess beyond face validity of the instrument, because of the absence of a conceptual foundation for the choice of indicators and the realization that each of the indicators was identified during brainstorming as a discreet measure of APN impact. In 
Table 1 Rank order and level of APN agreement with outcome indicators (maximum desirability score $=4 \cdot 0$ )

\begin{tabular}{|c|c|c|c|c|c|c|c|}
\hline \multirow[b]{2}{*}{ Outcome indicator } & \multirow[b]{2}{*}{$\begin{array}{l}\text { Rank } \\
\text { order }\end{array}$} & \multirow[b]{2}{*}{ Mean } & \multirow[b]{2}{*}{ SD } & \multicolumn{3}{|c|}{ Agree with } & \multirow{2}{*}{$\begin{array}{l}\text { Relationship } \\
\text { between keeping and } \\
\text { using indicator }(r)\end{array}$} \\
\hline & & & & $\begin{array}{l}\text { Ranking } \\
(\%)\end{array}$ & $\begin{array}{l}\text { Keeping } \\
(\%)\end{array}$ & $\begin{array}{l}\text { Using } \\
(\%)\end{array}$ & \\
\hline Satisfaction with care delivery & 1 & $3 \cdot 18$ & $0 \cdot 48$ & $92 \cdot 0$ & $98 \cdot 9$ & $98 \cdot 9$ & $1 \cdot 0$ \\
\hline Symptom resolution or reduction & 2 & $3 \cdot 14$ & $0 \cdot 49$ & $94 \cdot 3$ & $98 \cdot 9$ & $94 \cdot 3$ & $0 \cdot 77$ \\
\hline Perception of being well cared for & 3 & $3 \cdot 11$ & $0 \cdot 47$ & $94 \cdot 3$ & $98 \cdot 9$ & $97 \cdot 7$ & $0 \cdot 70$ \\
\hline Compliance/adherence & 4 & 3.09 & $0 \cdot 47$ & $73 \cdot 9$ & $89 \cdot 7$ & $89 \cdot 8$ & $0 \cdot 88$ \\
\hline Knowledge of patients and families & 5 & $3 \cdot 00$ & $0 \cdot 51$ & $85 \cdot 1$ & $88 \cdot 4$ & $88 \cdot 5$ & $1 \cdot 0$ \\
\hline Trust of care provider & 6 & $2 \cdot 99$ & $0 \cdot 47$ & $73 \cdot 3$ & $88 \cdot 2$ & $87 \cdot 1$ & 0.95 \\
\hline Collaboration among care providers & 7 & $2 \cdot 97$ & $0 \cdot 46$ & $79 \cdot 3$ & $91 \cdot 8$ & $88 \cdot 5$ & $0 \cdot 82$ \\
\hline Care provider recommendation according to need & 8 & $2 \cdot 95$ & $0 \cdot 51$ & $76 \cdot 5$ & $82 \cdot 6$ & $79 \cdot 1$ & $0 \cdot 89$ \\
\hline Frequency and type of procedures ordered & 9 & $2 \cdot 88$ & $0 \cdot 54$ & $66 \cdot 7$ & $76 \cdot 7$ & $72 \cdot 4$ & $0 \cdot 88$ \\
\hline Quality of life & 10 & $2 \cdot 87$ & $0 \cdot 50$ & $73 \cdot 6$ & $87 \cdot 2$ & $84 \cdot 9$ & 0.91 \\
\hline Accessibility of available services & 11 & $2 \cdot 83$ & $0 \cdot 53$ & $79 \cdot 3$ & $87 \cdot 1$ & $81 \cdot 8$ & $0 \cdot 83$ \\
\hline Use of appropriate services at appropriate times & 11 & $2 \cdot 83$ & $0 \cdot 46$ & $85 \cdot 1$ & $92 \cdot 0$ & $89 \cdot 7$ & $0 \cdot 87$ \\
\hline Care provider identification of gaps in service & 13 & $2 \cdot 82$ & $0 \cdot 54$ & $82 \cdot 8$ & $81 \cdot 0$ & $79 \cdot 3$ & $0 \cdot 93$ \\
\hline $\begin{array}{l}\text { Care provider recognition of need to } \\
\text { focus on patient goals }\end{array}$ & 14 & $2 \cdot 80$ & $0 \cdot 54$ & $66 \cdot 3$ & $81 \cdot 6$ & $79 \cdot 3$ & $0 \cdot 93$ \\
\hline Cost & 15 & $2 \cdot 79$ & $0 \cdot 46$ & $66 \cdot 7$ & $86 \cdot 0$ & $82 \cdot 8$ & $0 \cdot 88$ \\
\hline Postinteraction contact & 15 & $2 \cdot 79$ & $0 \cdot 55$ & $70 \cdot 5$ & $79 \cdot 3$ & $78 \cdot 2$ & $0 \cdot 90$ \\
\hline Productivity & 17 & $2 \cdot 77$ & $0 \cdot 70$ & $68 \cdot 6$ & $75 \cdot 3$ & $76 \cdot 7$ & $0 \cdot 90$ \\
\hline Family functioning & 18 & $2 \cdot 69$ & $0 \cdot 56$ & $75 \cdot 9$ & $74 \cdot 7$ & $72 \cdot 4$ & 0.94 \\
\hline Preference for APN as care provider & 19 & $2 \cdot 68$ & $0 \cdot 70$ & $62 \cdot 1$ & $69 \cdot 0$ & $65 \cdot 9$ & $0 \cdot 82$ \\
\hline $\begin{array}{l}\text { Patient preparedness for interventions and care } \\
\text { provider actions }\end{array}$ & 20 & $2 \cdot 66$ & $0 \cdot 59$ & $70 \cdot 9$ & $72 \cdot 4$ & $67 \cdot 8$ & $0 \cdot 90$ \\
\hline Patient self-directedness & 21 & $2 \cdot 65$ & $0 \cdot 65$ & $73 \cdot 6$ & $72 \cdot 9$ & $71 \cdot 3$ & 0.97 \\
\hline Functional status & 22 & $2 \cdot 64$ & $0 \cdot 74$ & $74 \cdot 7$ & $79 \cdot 5$ & $77 \cdot 3$ & 0.94 \\
\hline Patient self-esteem & 23 & $2 \cdot 60$ & $0 \cdot 58$ & $64 \cdot 0$ & $60 \cdot 5$ & $57 \cdot 0$ & 0.93 \\
\hline Knowledge and skill of other care providers & 24 & $2 \cdot 54$ & $0 \cdot 62$ & $70 \cdot 9$ & $54 \cdot 7$ & $51 \cdot 2$ & 0.93 \\
\hline Length of time in hospital & 25 & $2 \cdot 51$ & $0 \cdot 75$ & $65 \cdot 1$ & $61 \cdot 9$ & $54 \cdot 1$ & $0 \cdot 84$ \\
\hline Staff satisfaction with work & 26 & $2 \cdot 47$ & $0 \cdot 65$ & $70 \cdot 1$ & $70 \cdot 5$ & $64 \cdot 8$ & $0 \cdot 88$ \\
\hline $\begin{array}{l}\text { APN student awareness of need to evaluate } \\
\text { advanced practice role }\end{array}$ & 27 & $2 \cdot 33$ & $0 \cdot 63$ & $27 \cdot 9$ & $54 \cdot 7$ & $39 \cdot 5$ & $0 \cdot 72$ \\
\hline
\end{tabular}

${ }^{*} P<0.0001$ for all correlations.

addition, no comparable instruments were available for validation.

In the second survey, $50 \% \quad(n=88)$ of the original respondents completed and returned useable questionnaires. Of this number, 66-94\% agreed with the top 10 rankings. Percent agreement with keeping and intention to use the indicators likewise was high. The indicator rated the least consistently by APNs pertained to APN student awareness of the need to evaluate advanced practice role (28.4\% agreement with ranking and $39.8 \%$ intent to use) (See Table 1).

Responses pertaining to agreement with and intent to use the outcome were compared for evidence of consistency between agreement and intent. Each of these relationships was significant and ranged from 0.72 to $1 \cdot 0$. In general, respondents who recommended keeping and using indicators reflective of care delivery services (e.g. access to care or cost of care) also recommended other indicators associated with provision of services (e.g. identification of gaps in service and knowledge of other care providers). Those who favoured perceptual indicators (e.g. self-esteem or self-directedness) also supported the use of patient or care provider/learner perceptual outcomes. Correlations for these indicators ranged from 0.40 to 0.58 and were significant at $<0.0001$.

Analyses of responses according to respondent characteristics identified where response patterns differed. These differences were not consistent across indicators, however and because of the nonrepresentativeness of the sample, should be interpreted with caution. Because of the wide variety of APN role designations, three categories were used-nurse practitioner, clinical nurse specialist and other. Insufficient numbers also resulted in the collapsing of site of practice categories into organization-based, 
private group practice, independent practice and other. Table 2 summarizes the significant findings. In all cases, the ratings of the subgroup identified first in the table were significantly higher than the ratings of the comparison subgroup or groups.

No clear pattern of ratings is seen in Table 2, although some differences appear to reflect current role distinctions or locations of practice. For example, nurse practitioners, APNs working in rural areas and those in private group practice rated productivity higher than other APNs. This rating may reflect existing expectations for reimbursement decision making rather than likelihood of indicator usefulness for measuring APN effect. If so, the indicator is less valid as a global measure of APN outcome and is more reflective of role and site specific outcomes.

\section{DISCUSSION}

Despite many efforts to assure the accuracy of mailing lists, serious problems were evident. A number of individuals returned the questionnaires or called the investigators to report they were not at that time nor had they ever been practising as APNs. Others were retired or had moved from the state. In addition, a large number of undeliverables were returned. This problem, in combination with the low return rates, limits the generalizability of the study's findings.

Of the top 10 ranked indicators, five - patient satisfaction with care, symptom resolution/reduction, compliance/ adherence, knowledge of patient and family and quality of life - are indicators commonly recommended for measurement of care delivery outcome (Irvine et al. 1998). Two of the top 10 - perception of being well cared for and trust of care provider - are rarely discussed in widely promoted outcomes standards. The 'perception of being well cared for' indicator, however, is one that has been recommended recently by nurses experts, who suggest its focus may be more reflective of nursing's distinct contribution to care (Mitchell et al. 1997). Both these indicators require considerable effort to develop and test reliable and valid measures before they can be used successfully in determining APN impact. Nonetheless, their identification and their positive correlation with one another is an important finding. In a recent study of factors predictive of physician care provider outcome, trust in care provider was predictive of patient adherence to prescribed care, continuity with same provider and satisfaction with care (Thom et al. 1999).

Three of the top 10 indicators in our study were ranked similarly by a sample of psychiatric mental health APNs surveyed by Barrell et al. (1997). Patient satisfaction, which was ranked first in our study, was ranked ninth by the psychiatric mental health APNs. Symptom relief was ranked first in the Barrell et al. study (second in our study), while compliance was ranked tenth (fourth in our study). Indicators identified in the Barrell et al. study that were not mentioned in the current study were patient selfreports, goals set with patients, behavioural changes, attaining treatment plan goals, recidivism, community stays and family burden. Several of the indicators proposed by APNs in the Barrell et al. study focused on processes of care or were specific to mental health populations.

Three other top 10 indicators - collaboration among care providers, care provider recommendation according to need and frequency and type of procedures ordered are indicators of care delivery process rather than outcome. These indicators would be reasonable measures of intermediate outcome, with the expectation that improvements in collaboration, care provider recommendation of action based on patient need and frequency and type of procedures ordered would ultimately result in improved care delivery outcome for patients. The use of these indicators may be seen as an intermediate step, however and should be clearly identified as indicators of care processes that ultimately result in changes in care delivery outcomes.

Of interest in the ranking of the proposed outcome indicators is the relatively low placement of cost, postinteraction contact by patient and functional status. These indicators are commonly recommended for inclusion as measures of nursing outcomes (Irvine et al. 1998). Comments made by APNs during the brainstorming session provide some insight into why these indicators were rated low. Cost as an outcome indicator generated the most disagreement among practitioners participating in the brainstorming. Some thought it was necessary to include cost because of the cost-driven environment in which APNs practice. Others noted its historical usefulness in demonstrating care equivalent to medical care at reduced cost. Still others commented on the unreliability of cost as an indicator of APN practice. They noted that the cost of services is routinely set by external reimbursers, which eliminates the potential for variability across providers regardless of quality or efficiency of care. Although these concerns are legitimate, the importance payers place on cost as an outcome suggests APNs would be well served to monitor this aspect of care delivery outcome.

The postinteraction contact indicator also prompted discussions about whether increased or decreased contact was a desirable indicator. Some APNs noted that increased contact demonstrates evidence that patients and families feel comfortable with initiating contacts in response to recognized needs and concerns. Others reported that decreased contact denotes evidence of comprehensive teaching and preparatory work during the initial contact. These differences in perception about the directionality of postinteraction contact may have contributed to the ranking seen. 
G.L. Ingersoll et al.

Table 2 Respondent characteristics and indicator rating

\begin{tabular}{|c|c|c|c|c|}
\hline Respondent characteristic & Indicator & Mean (SD) & $F$ (d.f.) & $p$ \\
\hline Age (years) & Preference for APN as care provider & & & \\
\hline $25-34$ & & $31 \cdot 5(5 \cdot 2)$ & $4 \cdot 61(3)$ & $0 \cdot 004$ \\
\hline $45-54$ & & $26 \cdot 2(6 \cdot 6)$ & & \\
\hline$>55$ & & $23 \cdot 1(7 \cdot 4)$ & & \\
\hline Years worked as APN & APN student awareness of need to evaluate role & & & \\
\hline $1-5$ & & $14 \cdot 7(3 \cdot 7)$ & $3 \cdot 77(2)$ & $0 \cdot 025$ \\
\hline \multirow[t]{2}{*}{$>10$} & & $12 \cdot 9(3 \cdot 6)$ & & \\
\hline & Preference for APN as care provider & & & \\
\hline $1-5$ & & $29 \cdot 3(6 \cdot 2)$ & $7 \cdot 03(2)$ & $0 \cdot 001$ \\
\hline $6-10$ & & $25 \cdot 8(7 \cdot 1)$ & & \\
\hline \multirow[t]{2}{*}{$>10$} & & $24 \cdot 9(7 \cdot 1)$ & & \\
\hline & Staff satisfaction with work & & & \\
\hline $1-5$ & & $15 \cdot 8(4 \cdot 0)$ & $4 \cdot 66(2)$ & $0 \cdot 011$ \\
\hline \multirow[t]{2}{*}{$>10$} & & $13 \cdot 7(3 \cdot 7)$ & & \\
\hline & Quality of life & & & \\
\hline $6-10$ & & $30 \cdot 2(4 \cdot 8)$ & $3 \cdot 52(2)$ & $0 \cdot 032$ \\
\hline \multirow[t]{2}{*}{$>10$} & & $27 \cdot 6(5 \cdot 6)$ & & \\
\hline & Symptom resolution or reduction & & & \\
\hline $6-10$ & & $33 \cdot 0(4 \cdot 3)$ & $4 \cdot 30(2)$ & $0 \cdot 015$ \\
\hline$>10$ & & $30 \cdot 2(4 \cdot 8)$ & & \\
\hline APN role & Productivity & & & \\
\hline Nurse practitioner & & $22 \cdot 6(5 \cdot 5)$ & $4 \cdot 17(2)$ & $0 \cdot 02$ \\
\hline \multirow[t]{2}{*}{ Clinical nurse specialist } & & $18 \cdot 7(5 \cdot 6)$ & & \\
\hline & Symptom resolution or reduction & & & \\
\hline Clinical nurse specialist & & $33 \cdot 9(3 \cdot 3)$ & $6 \cdot 42(2)$ & $0 \cdot 002$ \\
\hline Nurse practitioner & & $31 \cdot 4(4 \cdot 8)$ & & \\
\hline \multirow[t]{2}{*}{ Other } & & $26 \cdot 8(5 \cdot 2)$ & & \\
\hline & Patient self-esteem & & & \\
\hline Clinical nurse specialist & & $30 \cdot 7(5 \cdot 3)$ & $5 \cdot 72(2)$ & $0 \cdot 004$ \\
\hline Nurse practitioner & & $25 \cdot 5(5 \cdot 6)$ & & \\
\hline Site of practice & Knowledge of patients and families & & & \\
\hline Independent practice & & $34 \cdot 0(4 \cdot 8)$ & $2 \cdot 87(3)$ & $0 \cdot 04$ \\
\hline Organization-based practice & & $26 \cdot 4(4 \cdot 6)$ & & \\
\hline \multirow[t]{2}{*}{ Private group practice } & & $26 \cdot 6(6 \cdot 3)$ & & \\
\hline & Preference for APN as care provider & & & \\
\hline Private group practice & & $29 \cdot 5(5 \cdot 7)$ & $7 \cdot 01(3)$ & $0 \cdot 0002$ \\
\hline \multirow[t]{2}{*}{ Organization based practice } & & $24 \cdot 2(7 \cdot 1)$ & & \\
\hline & Productivity & & & \\
\hline Private group practice & & $23 \cdot 9(4 \cdot 6)$ & $2 \cdot 99(3)$ & $0 \cdot 03$ \\
\hline \multirow[t]{2}{*}{ Organization-based practice } & & $21 \cdot 0(6 \cdot 1)$ & & \\
\hline & APN student awareness of need to evaluate role & & & \\
\hline Private group practice & & $15 \cdot 0(3 \cdot 6)$ & $2 \cdot 69(3)$ & $0 \cdot 05$ \\
\hline \multirow[t]{2}{*}{ Organization-based practice } & & $13 \cdot 1(3 \cdot 6)$ & & \\
\hline & Postinteraction contact & & & \\
\hline Independent practice & & $32 \cdot 4(1 \cdot 5)$ & $4 \cdot 06(3)$ & $0 \cdot 008$ \\
\hline Organization-based practice & & $26 \cdot 4(4 \cdot 9)$ & & \\
\hline Geographic location of practice & Postinteraction contact & & & \\
\hline Mixed urban and rural & & $29 \cdot 6(4 \cdot 9)$ & $4 \cdot 13(2)$ & $0 \cdot 018$ \\
\hline Urban & & $26 \cdot 6(5 \cdot 1)$ & & \\
\hline
\end{tabular}


Table 2 (Continued)

\begin{tabular}{|c|c|c|c|c|}
\hline Respondent characteristic & Indicator & Mean (SD) & $F$ (d.f.) & $p$ \\
\hline $\begin{array}{l}\text { Mixed urban and rural } \\
\text { Urban }\end{array}$ & Knowledge and skill of other care providers & $\begin{array}{l}24 \cdot 6(5 \cdot 4) \\
21 \cdot 9(4 \cdot 6)\end{array}$ & $3 \cdot 32(2)$ & $0 \cdot 04$ \\
\hline $\begin{array}{l}\text { Mixed urban and rural } \\
\text { Rural } \\
\text { Urban }\end{array}$ & Staff satisfaction with work & $\begin{array}{l}16 \cdot 2(3 \cdot 6) \\
15 \cdot 5(4 \cdot 2) \\
13 \cdot 7(3 \cdot 6)\end{array}$ & $7 \cdot 34(2)$ & $0 \cdot 0009$ \\
\hline $\begin{array}{l}\text { Rural } \\
\text { Urban }\end{array}$ & Preference for APN as care provider & $\begin{array}{l}28 \cdot 7(6 \cdot 3) \\
25 \cdot 3(7 \cdot 3)\end{array}$ & $4 \cdot 05(2)$ & $0 \cdot 019$ \\
\hline $\begin{array}{l}\text { Rural } \\
\text { Urban }\end{array}$ & Productivity & $\begin{array}{l}23 \cdot 6(4 \cdot 9) \\
20 \cdot 9(5 \cdot 7)\end{array}$ & $3 \cdot 74(2)$ & $0 \cdot 026$ \\
\hline $\begin{array}{l}\text { Primary care provider } \\
\text { (PCP) status } \\
\text { No designation as PCP } \\
\text { Designation as PCP }\end{array}$ & Compliance/adherence & $\begin{array}{l}31 \cdot 7(4 \cdot 7) \\
30 \cdot 1(4 \cdot 6)\end{array}$ & $4 \cdot 57(1)$ & $0 \cdot 034$ \\
\hline $\begin{array}{l}\text { No designation as PCP } \\
\text { Designation as PCP }\end{array}$ & Patient self-esteem & $\begin{array}{l}26 \cdot 9(6 \cdot 2) \\
24 \cdot 9(5 \cdot 1)\end{array}$ & $5 \cdot 42(1)$ & $0 \cdot 021$ \\
\hline $\begin{array}{l}\text { No designation as PCP } \\
\text { Designation as PCP }\end{array}$ & Patient self-directedness & $\begin{array}{l}27 \cdot 5(7 \cdot 4) \\
25 \cdot 2(4 \cdot 9)\end{array}$ & $4 \cdot 76(1)$ & $0 \cdot 031$ \\
\hline $\begin{array}{l}\text { No designation as PCP } \\
\text { Designation as PCP }\end{array}$ & $\begin{array}{l}\text { Care provider recognition of need to focus on } \\
\text { patient goals }\end{array}$ & $\begin{array}{l}28.9(5 \cdot 9) \\
26.9(4 \cdot 5)\end{array}$ & $4 \cdot 95(1)$ & $0 \cdot 028$ \\
\hline $\begin{array}{l}\text { No designation as PCP } \\
\text { Designation as PCP }\end{array}$ & $\begin{array}{l}\text { Patient preparedness for interventions and care } \\
\text { provider actions }\end{array}$ & $\begin{array}{l}27 \cdot 8(6 \cdot 1) \\
25 \cdot 2(5 \cdot 4)\end{array}$ & $7 \cdot 76(1)$ & $0 \cdot 006$ \\
\hline $\begin{array}{l}\text { Usual daily patient caseload } \\
21-50 \text { patients } \\
<10 \text { patients }\end{array}$ & Productivity & $\begin{array}{l}23 \cdot 5(6 \cdot 6) \\
19 \cdot 7(4 \cdot 6)\end{array}$ & $3 \cdot 59(3)$ & $0 \cdot 015$ \\
\hline
\end{tabular}

Of note in this discussion is the problem of directionality with outcome indicators. Ideally, outcome indicators should be kept direction free to allow for the assessment of the entire range of possible changes and facilitate collection and interpretation of accurate data.

The low ranking of functional status also is of interest. Little discussion of this indicator occurred during brainstorming. Some participants did note, however, that physical condition, age and mental outlook might be more influential in determining physical functioning than care delivery by APNs and colleagues. This perception may have resulted in a concern about the indicator's sensitivity to APN effect. The lower rankings for knowledge of other care providers, length of time in hospital, staff satisfaction and APN student awareness of need to evaluate advanced practice role provide some support for the validity of the ranking process. Because the study focused on identifying indicators common to all APNs regardless of location or specialty, the lower rankings of these acute care and educationally focused indicators is expected.

Some of the indicators recommended in this study are consistent with measures used by previous researchers to assess APN effect. The most frequently used indicator is patient satisfaction, which was measured by Mundinger et al. (2000), Naylor et al. (1994), Brooten and Naylor (1995) and Aiken et al. (1993). Functional status also has been used regularly (Aiken et al. 1993, Naylor et al. 1994, Naylor \& McCauley 1999), as has use of services, although previous investigators have focused on the frequency rather than the appropriate use of services (Aiken et al. 
1993, Naylor et al. 1994, Brooten \& Naylor 1995, Mundinger et al. 2000). Cost has been used in the Brooten et al. studies (Naylor et al. 1994, Brooten \& Naylor 1995), although differences in reporting formats are found. Most estimates in these studies used hospital and resource use charges, which provide only a portion of the data needed to determine actual cost.

Indicators used in previous research that were not identified in this study, but which may be useful for measuring APN impact, include family functioning, care giver burden, perception of overall health (Naylor et al. 1994) and self-care management (Aiken et al. 1993). Previous studies also have used population-focused outcomes, which should be incorporated along with core indicators in any comprehensive assessment of APN effect.

Outcome indicators recommended in this study do not fit readily with any of the previous categorizations of outcomes. The closest fit is Hegyvary's (1991) clinical, functional, financial and perceptual classification, although a more precise classification might be perceptual, behavioural, physical/psychosocial and financial. Further refinement would suggest outcome categorizations of health status (individual and family), perceptions about self and service, health behaviour (individual and family), decision-making and cost. These categories also would allow for classification of indicators identified by others (e.g. family functioning, caregiver burden, perception of overall health and self-care management).

\section{CONCLUSIONS}

In this study, 27 core outcome indicators were identified and rated as to their potential usefulness for measuring APN impact on care delivery outcome. The top 10 indicators include several used in previous research, as well as some that are as yet untested. Additional research is needed to determine whether or not the proposed indicators are sensitive to and reflective of APN care. The current study provides an initial step to demonstrate APN effect on care outcomes.

\section{Acknowledgements}

The authors acknowledge with appreciation the partial funding of this study by the Vanderbilt University Research Council, the Vanderbilt University School of Nursing and the TNA. Thanks also are extended to those who participated as facilitators of the study's initial focus groups and the APNs who contributed their time and expertise to the focus groups, the instrument pilot testing and the survey components of the study. Further appreciation is extended to Dr Patricia Smith at Eastern Tennessee State University School of Nursing for assistance with the identification of APNs in Tennessee.

\section{References}

Aiken L.H., Lake E.T., Semann S., Lehman H.P., O’Hare P.A., Cole C.S., Dunbar D. \& Frank I. (1993) Nurse practitioner managed care for persons with HIV infection. Image: Journal of Nursing Scholarship 25, 172-177.

American Nurses Association (1996a) Nursing Quality Indicators: Definitions and Implications. ANA, Washington, DC.

American Nurses Association (1996b) Scope and Standards of Advanced Practice Registered Nursing. ANA, Washington, DC.

Anderson C.A. \& Bednash G. (1996) Summer seminar marks new chapter for AACN. Syllabus 22, 2.

Barrell L.M., Merwin E.I. \& Poster E.C. (1997) Patient outcomes used by advanced practice psychiatric nurses to evaluate effectiveness of practice. Archives of Psychiatric Nursing 11, 184-197.

Brooten D. \& Naylor M.D. (1995) Nurses' effect on changing patient outcomes. Image: Journal of Nursing Scholarship 27, 95-99.

Brown S.J. (1998) A framework for advanced practice nursing. Journal of Professional Nursing 14, 157-164.

Buerhaus P.I. (1998) Medicare payment for advanced practice nurses: what are the research questions? Nursing Outlook 46, 151-153.

Division of Health Related Boards. (1995) Administrative rules of the Tennessee Board of Nursing, March 1996. Tennessee Department of Health, Nashville, TN.

Hegyvary S.T. (1991) Issues in outcomes research. Journal of Nursing Quality Assurance 5, 1-6.

Hylka S.C. \& Beschle J.C. (1995) Nurse practitioners, cost savings, and improved patient care in the department of surgery. Nursing Economics 13, 349-354.

Ingersoll G.L. (1995) Evaluation of the advanced practice nurse role in acute/specialty care. Critical Care Nursing Clinics of North America 7, 25-33.

Irvine D., Sidani S. \& McGillis Hall L. (1998) Linking outcomes to nurses' roles in health care. Nursing Economics 16, 58-64.

Jennings B.M. (1991) Patient outcomes research: seizing the opportunity. Advances in Nursing Science 14, 59-72.

Johnson M. \& Maas M. (eds) (1997). Nursing Outcomes Classification (NOC). Mosby-Year Book, St Louis.

Kelly K.C., Huber D.G., Johnson M., McCloskey J.C. \& Maas M. (1994) The medical outcomes study: a nursing perspective. Journal of Professional Nursing 10, 209-216.

Lang N.M. \& Marek K.D. (1990) The classification of patient outcomes. Journal of Professional Nursing 6, 158-163.

Maas M.L., Johnson M. \& Moorhead S. (1996) Classifying nursingsensitive patient outcomes. Image: Journal of Nursing Scholarship 28, 295-301.

Mark B.A. \& Burleson D.L. (1995) Measurement of patient outcomes. Data availability and consistency across hospitals. Journal of Nursing Administration 25, 52-58.

McCloskey J.C. \& Bulechek G.M. (eds) (1996) Iowa Interventions Project. Nursing Interventions Classification (NIC) 2nd edn. Mosby-Year Book, St Louis.

Mitchell P.H., Heinrich J., Moritz P. \& Hinshaw A.S. (1997) Outcome measures and care delivery systems. Introduction and purposes of conference. Medical Care 35, NS1-NS5.

Mundinger M.O. (1994) Advanced practice nursing - good medicine for physicians? New England Journal of Medicine 330, 211-214. 
Mundinger M.O., Kane R.L., Lenz E.R., Totten A.M., Tsai W.Y., Cleary P.D., Friedewald W.T., Siu A.L. \& Shelanski M.L. (2000) Primary care outcomes in patients treated by nurse practitioners or physicians. A randomized trial. Journal of American Medical Association 283, 59-68.

Naylor M.D. \& McCauley K.M. (1999) The effects of a discharge planning and home follow-up intervention on elders hospitalized with common medical and surgical conditions. Journal of Cardiovascular Nursing 14, 44-54.

Naylor M., Brooten D., Jones R., Lavizzo-Mourey R., Mezey M. \& Pauly M. (1994) Comprehensive discharge planning for the hospitalized elderly. A randomized clinical trial. Annals of Internal Medicine 120, 999-1006.

Reed C.A. \& Selleck C.S. (1996) The role of midlevel providers in cancer screening. Medical Clinics of North America 80, 135-144.

Safriet B.J. (1992) Health care dollars and regulatory sense: the role of advanced nursing practice. Yale Journal on Regulation 9, 417-488.
Sidani S. \& Irvine D. (1999) A conceptual framework for evaluating the nurse practitioner role in acute care settings. Journal of Advanced Nursing 30, 58-66.

Sox H.C. (2000) Independent primary care practice by nurse practitioners. Journal of American Medical Association 283, 106-108.

Tennessee Board of Nursing. (1994, November) Law Regulating the Practice of Nursing. State of Tennessee Department of Health, Nashville, TN.

Thom D.H., Ribisl K.M., Stewart A.L., Luke D.A. \& The Stanford Trust Study Physicians (1999) Further validation and reliability testing of the trust in physician scale. Medical Care 37, 510-517.

Werley H.H., Devine E.C., Zorn C.R., Ryan P. \& Westra B.L. (1991) The nursing minimum data set: abstraction tool for standardized, comparable, essential data. American Journal of Public Health 81, 424-426. 